
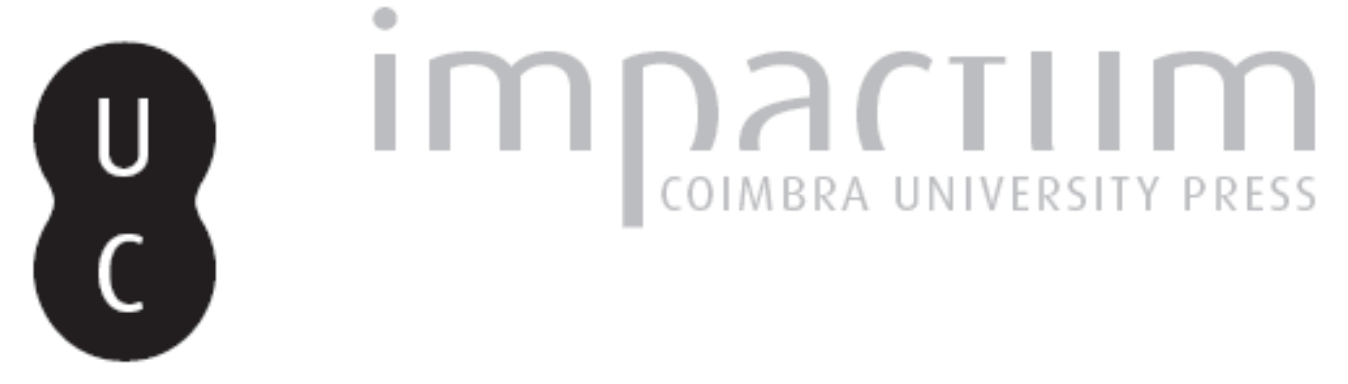

\title{
A presidência portuguesa da União Europeia e o desenvolvimento de sistemas de alerta precoce
}

Autor(es): $\quad$ Mendes, Carlos; Martins, Ana

Publicado por: Associação Portuguesa de Riscos, Prevenção e Segurança

URL persistente:

URI:http://hdl.handle.net/10316.2/36202

DOI:

DOI:http://dx.doi.org/10.14195/1647-7723_15_8

Accessed : $\quad$ 26-Apr-2023 14:04:03

A navegação consulta e descarregamento dos títulos inseridos nas Bibliotecas Digitais UC Digitalis, UC Pombalina e UC Impactum, pressupõem a aceitação plena e sem reservas dos Termos e Condições de Uso destas Bibliotecas Digitais, disponíveis em https://digitalis.uc.pt/pt-pt/termos.

Conforme exposto nos referidos Termos e Condições de Uso, o descarregamento de títulos de acesso restrito requer uma licença válida de autorização devendo o utilizador aceder ao(s) documento(s) a partir de um endereço de IP da instituição detentora da supramencionada licença.

Ao utilizador é apenas permitido o descarregamento para uso pessoal, pelo que o emprego do(s) título(s) descarregado(s) para outro fim, designadamente comercial, carece de autorização do respetivo autor ou editor da obra.

Na medida em que todas as obras da UC Digitalis se encontram protegidas pelo Código do Direito de Autor e Direitos Conexos e demais legislação aplicável, toda a cópia, parcial ou total, deste documento, nos casos em que é legalmente admitida, deverá conter ou fazer-se acompanhar por este aviso.

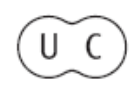




\section{territorium}

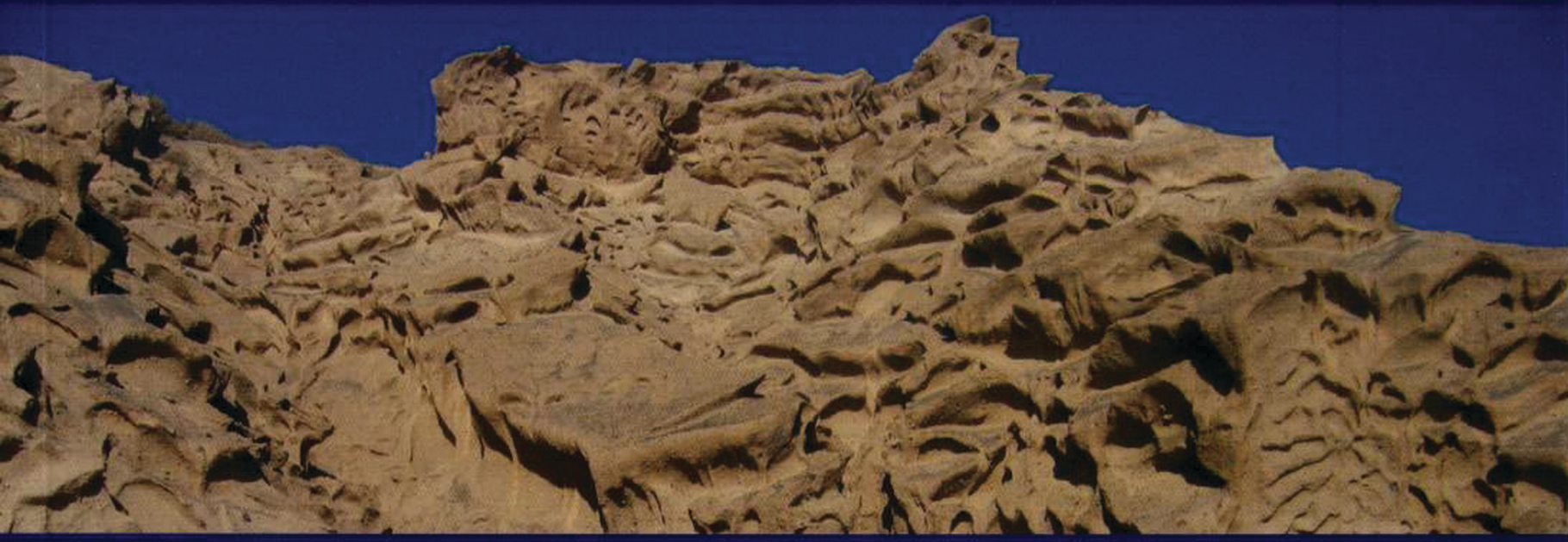

15

Revista da Associação Portuguesa de Riscos, Prevenção e Segurança 2008 


\section{A Presidência Portuguesa da União Europeia e o Desenvolvimento de Sistemas de Alerta Precoce*}

Carlos Mendes; Engenheiro do Ambiente; Autoridade Nacional de Protecção Civil; carlos.mendesQprociv.pt Ana Martins; Psicóloga; Autoridade Nacional de Protecção Civil; ana.martins@prociv.pt Margarida Leitão; Antropóloga; Autoridade Nacional de Protecção Civil; margarida. leitao@prociv.pt

\section{Resumo}

Portugal assumiu, durante o segundo semestre de 2007, a Presidência do Conselho da União Europeia, cabendo-Ihe, em estreita cooperação com as restantes Estados-Membros e com a Comissão Europeia, a conđução dos trabalhos europeus em matéria de Protecção Civil. De entre as áreas programáticas e os dojectivas estratégicas traçadas, contou-se o impulso dado ao estabelecimento e ao desenvolvimento de sistemas de alerta precoce na União Frropeia.

\section{Intrợução}

O tsunami ocorrido no Oceano Índico, em Dezembro de 2004, originou cerca de 250.000 vítimas mortais, espal hou uma vaga de destnuição em diversos países e causou enommes perdas económicas. A ausência de sistemas de alerta precoce depressa foi identificada como um factor-chave responsável pela falta de aviso à população. Se um sistema deste tipo existisse no Oceano Índico, aquando do tsunami, vidas poderiam ter sido salvas e as danos nos bens e no ambiente teriam sido atenuados.

Após esta catástrofe, a discussão convergiu para a importância dos sistemas de detecção e alerta precoce, especialmente em outras áreas vilneráveis. Pouco tempo após o tsunami, a Conferência Mundial da Estratégia Intemacional para a Redução de Desastres das Nações unidas reconhecia que os sistemas de alerta constituíam umelemento importantena redução das vilnerabi 7 idades e das consequências das catástrofes, assumindo-se como uma ferramenta fundamental para o aumento da resi 7 iência das países e cas comunidades.

Cedo se percebeu também que o desenvolvimento de sistemas de alerta precoce se relaciona com outro desafio: o da comunicação de risco. En cada ano, mais de 100 mi 7 hões de cidadãos atravessam as fronteiras intemas da União Frropeia. Nb entanto, devidb a razões relacionadas coma barreira linguística ou a ausência de informação sobre os riscos, a maior parte dos cicadãos sente-se inseguro, pois não reconhece nem os sinais de alerta nemas instnuções de emergência quando está ausente do seu país. Esta situação atesta a necessidade de receber informação fidedigna e adequada (na forma de sinais, símbolos e autras formas de aviso), de modo a aumentar o sentimento de protecção dos cidadãos.

Durante situações de emergência em território estrangeiro, seja no caso de um sismo, uma cheia ou uma avalanche, os cidadãos devem ser capazes de compreender o que as autoridades locais e a pqujlação desse país querem transmitir, demoob a se protegerem a si e aos seus. No entanto, as respostas naturais a emergências por parte dos cidadãos afectados são, normalmente, as erradas. As pessoas tendem a correr, ficarem fora das suas habitações ou, pior ainda, serem espectadores de um incidente. Estas acções são inevitavelmente as erradas e induzem um aumento de acidentes - consequência que pode ser maior se a emergência ocorrer numa região com uma população turista de di ferentes nacional idades, a qual pooleránão ser capaz de responder a um sinal acústico de alerta ou de compreender o seu significado.

\section{Sistemas de alerta precoce na União Europeia}

Na União Europeia, o enfoque no desenvolvimento de sistemas de alerta precoce tem sido uma constante. Ná realidade, tanto as Estados-Membros como a Comissão Europeia já desenvolveram diversos esforços para estabelecer Sistemas deAlerta Precoce. Iniciativas como o EFAS (sistema dealertapara cheias), HFHIS (incêndios florestais), Ecurie (emergências radiológicas) ou Meteoalarm (situações meteorológicas ađversas) são elucidativas de boas práticas a nível europeu que têm sidb exercidas neste domínio.

Apesar da constatação de que os sistemas de alerta precoce contribuem significativamente para a redução das custos das desastres, tanto en termos de percas de vidas humanas como de danos na propriedade, várias lacunas têm sido identificadas. Por issomesmo, em 18 de Julho de 2005, o Conselho Europeu (que reúne os chefes de Estado e de Govemo das diversas países da União Europeia) convidou a Comissão Europeia a reforçar as sistemas de detecção e de alerta precoce existentes. Mais recentemente, en 2007, a revisão do Mecanismo Comunitário de Protecção Civil reiterou a importância de actividades a nível comunitário que contribuam para o desenvolvimento de sistemas de detecção e alerta precoce emmatéria de catástrofes que possam afectar o território das Estadas-Mendoras.

\footnotetext{
* Comunicação apresentada ao IV Encontro Nacional de Riscos, Coimbra, 10 de Março de 2008.
} 


\section{Desafios para a Presidência Portuguesa}

Ao preparar o programa de acção para a Presidência do Conselho da União Europeia na área da protecção civil, Portugal considercu a importância deste tena, não só por estar directamente relacionado coma protecção das populações, como também porque poderá auxi liar os Estados-Membros na diminuição da resposta a catástrofes, realçando a capacidade europeia colectiva para uma reacção rápida. Procurou-se assim ter uma visão a médio e longo prazo, com o objectivo de melhorar o grau de autoprotecção da população e de alcançar progressivamente uma área comum segura para mi lhões de cidadãos europeus.

Neste sentido, julgou-se fundamental a adopção de passas concretas tendo em vista o estabelecimento e desenvolvimento de sistemas de detecção e alerta precoce, demodb a proteger o território das EstadosMembros. Tais sistemas deveriam ser centrados nos util izadores finais e integrar quatro elementos básicos: i) conhecimentos das riscos;

ii) equipamento técrico de alerta e demonitorização; iii) difusão dealertas significativos às pesscas emrisco; iv) sensibi lização pública e preparação.

Por attro ladb, foi considerado ser devital importânciao desenvolvimento de cirectrizes relativas a sinais comns de alerta que possam ser compreendidas por toolos as cidadãos, independentemente do seu país de origem ou da língua que falam. Emparticular, considerou-se a importância dos sinais de alerta estarem relacionados não com o tipo de emergência mas com o comportamento esperado por parte da população quanto a procedimentos simples e universais: a "evacuação para uma área segura" e a "procura de um local abrigado e seguro". Como tal, para estes dois procedimentos deveriamexistirdois sinais dealerta associadbs.

\section{Acções desenvolvidas durante a Presidência Portuguesa}

A estratégia del ineada para a introoução da temática dos sistemas de alerta precoce na agenda da Presidência Portuguesa assentou na criação prévia de condições para uma abordagem técnica e científica destinada a criar a sustentação e a base de apoio necessárias à negociação de um documento de carácter político a ser aprovado pelos Ministros da Administração Interna dos 27 Estados-Membros da União Europeia.

Para estimular este debate e desencadear tal processo, Portugal acolheu, sob organização conjunta da Autoridade Nacional de Protecção Civil (ANPC) e da
Comissão Frropeia, um seminário intemacional sobre sistemas de alerta precoce que reuniu cerca de 120 especialistas de 20 Estados-Menoros, de organizações internacionais e de países terceiros com ampla experiência na implementação de sistemas de alerta, nomeadamente as Estados Unidas da América ou o Japão.

O seminário visou discutir o estado da arte na União Europeia quanto a sistemas de alerta, de modo a identificar lacunas existentes e a del inear as bases para um plano de acção destinado a supri-las. De igual modo, o seminário procurou debater assuntos transversais, tais como o desenvolvimento de directrizes para o estabelecimento de sinais comuns de alerta a nível europeu.

Após três đias de troca de experiências e conhecimentos, os peritos concluíram que toolos os países da União possuemuma estratégia nacional para anál ise de risco e alerta precoce, para a qual a entidade responsável pela emissão do alerta (nomalmente a autoridade competente de protecção civi l) trabalha en colaborração com autras entidades ténicas e científicas. Cantudb, cadapaís tem as suas especificicidades devido ao facto de enfrentar perigos diferentes (por exemplo, vilcões, sismose tsunamis são importantes para os países do Sul da Europa, enquanto as tempestades de vento são importantes no Norte) e à existência de realicades distintas quanto à responsabi 7 idade de aviso à população (nalguns casas localizadaanível central; natroscasos, anível muicipal) .

Ficou ainda evidenciado que, embora a maior parte dos riscas esteja já coberta por sistemas de alerta, existem lacunas que importa suprimir, nomeadamente deficiências na troca de informação em tempo real, insuficiências na cartografia de risco, ausência de sinais de aviso para turistas emetoolologias comuns de aviso à população.

Por fim, os peritos concordaram com as linhas estratégicas a adoptar para o desenvolvimento de sistemas de alerta precoce, nomeadamente o envolvimento das diversos uti 7 izadores finais (demodb a conseguir adequar a informação, evitando o pânico em situações de emergência) e o aproveitamento de boas práticas ao nível da cooperação transfronteiriça. As sistemas de alerta multi-riscas foram também considerados como uma prioridade para a redução de desastres.

Com base nas conclusões do seminário e nos resultados dos trabalhos desenvolvidos pela Comissão Frropeia, ao nível de gnupos de peritos, foi possível a Portugal negociar com as restantes EstadosMembros um documento de Conclusões do Conselho 
da União Europeia, o qual traduz compromissos e intenções de carácter político a serem seguidos na União. As negociações desse documento prolongaram-se ao longo de dois meses em sede do Grupo de Trabalho de Protecção Civil do Conselho (PROCIV) , o qual foi presidido pela ANPC ao longo do segundo semestre de 2007.

Apesar das reticências iniciais, foi passível chegar a acordo e no Conselho de Justiça e Assuntos Intemos de 5 e 6 de Dezembro de 2007 os Ministros da Administração Interna dos 27 Estados-Membros adoptaram por unanimidade a iniciativa portuguesa e as suas propostas de actuação futura por parte da Comissão e dos Estados-Membros. O documento aprovado divide-se em duas componentes: uma que segue uma abordagem global de carácter multi-riscos (Conclusões do Conselho sobre o desenvolvimento e estabelecimento de sistenas de alerta precoce na União Frropeia) , e outra direccionada exclusivamente para o risco de tsunamis (Conclusões do Conselho sobre o desenvolvimento de um sistena de alerta precoce para tsunamis no Atlântico Nordeste e no Mediterrâneo) .

\section{Compromissos e intenções}

As Conclusões do Conselho sublinham a responsabilidade dos Estados-Membros de protegerem contra catástrofes as pessoas e os bens localizados no seu território, nomeadamente no que respeita à prestação efectiva de informações en tempo útil aos cidadãos em perigo. Além disso, salientam que "os sistemas de alerta precoce devem ser adaptados à evolução dos riscos, decorrente do crescimento demográfico, das efeitos das alteraçōes climáticas e da crescente mobilidade", sendo todos estes elementos responsáveis pelo aumento da vulnerabilidade das sociedades modemas.

O documento define ainda princípios básicos para o desenvolvimento de sistemas de alerta precoce na União Europeia, designadamente:

- evitar duplicações, reforçando e valorizando os sistemas e as capacidades existentes,

- respeitar as responsabilidades dos EstadosMembros e incentivar o desenvolvimento de capacidades nacionais,

- promover a interconexão entre as capacidades dos Estados-Membros,

- incentivar a implementação de sistemas operacionais 24 horas por dia, 7 dias por semana,

- ser eficaz e eficiente em termos de austos.

Apesar de se congratular com os progressos registados pela Comissão e pelos Estados-Membros no que respeita à criação e instalação de sistemas de alerta precoce, o Conselho da União Europeia considerou que subsistemainda lacunas e deficiências, salientanob, emparticular, as existentes a nível dos métoobs de alerta, principalmente no que diz respeito aos sinais de aviso que poderão não chegar, nem ser compreendidos, ou resultar no comportamento adequado de todas as pessoas em risco, nomeadamente de estrangeiros, turistas ou cidadãos que tenham dificuldades auditivas au visuais.

Nestecontexto, foi.solientadaa importânciaceintensificar o debate sobre abordagens nomal izadas para alertar as cidadãos da União, tendo as Estadas-Membros sido encorajadbs a criar programas de educação destinados às commidades locais em áreas de risco e a lançar campanhas de sensibil ização da população e dos turistas a fimde evitar opânico encaso de falsos alames. Especial atenção foi tambén dada à cooperação transfronteiriça neste domínio, tendo sido recamendado aos EstadosMembros vizinhos o desenvolvimento da interqperabilidade e capossível interligação de sistemas de alerta precoce existentes, de modo a estabelecer métodos comuns para alertar as populações em zonas fronteiriças. Jáno que respeita às acçōes da Comissão Europeia, o Conselho recomendou que esta se deva empenhar em promover abordagens multi-riscos e em identificar zonas de elevado risco, promovenob a partitha de dadas e de mensagens de alerta em tempo real entre os Estados-Mentoros e entre estes e países terceiros.

Aatro nível, o Conselho registau compreocupação quea inexistênciadeumsistemadealertapara riscos costeiros, como os tsunamis, constitui uma laduna importante que importa preencher. Esta deficiência ganha umpeso maior se se recordar que a região do Nbrdestedb At] lântico edb Mediterrâneo é a única região de risco, a nível mundial, que não está coberta, na sua maior parte, por qualquer sistema qperacional de alerta precoce para a cconrência de tsunamis, não dostante o facto depoderemvir a ccomer maremotos de grandes dimensões (como já aconteceu no passadb) a aja forçadestruidora.se estenca a zonas costeiras densamente povoadas e al tamente industrializadas em muitos Estadas-Mentoros.

Assim, foi considerado que toodas as Estadas-Menbros (mesmo os não directamente vulneráveis a tsunamis) deverão intrinsecamente ter interesse na criação de um sistema de alerta para tsunamis, tendo sido recomendado ummaior envolvimento com a iniciativa da Comissão Oceanográfica Intergovemamental da UNESCO actualmente em curso e que visa a criação de um Sistema de Alerta e Mitigação dos Ffeitos de Tsunamis no Nordeste do Atlântico, no Mediterrâneo e nos Mares Adjacentes (NEAMIUS, sigla em inglês) . 


\section{Conclusões}

Odesenvolvimento de sistemas de alertaprecocena união Elropeia foi uma prioridade assumida por Portugal para o segundo semestre de 2007, período em que deteve a Presidência do Conselho da União. Subjacente a esta prioridade estava o desejo nacional de contribuir para o fortalecimento de uma verdadeira all tura de protecção civil errqpeia que constituŕsse uma expressão visível da solidariedade entre os Estados-Membros, numa lógica de parti tha de informação de base e de suporte mútuo em situação de energência.

As primeiras reaç̧ões de outros Estados-Membros à proposta portuguesa de abordar e abter compromissos sobre esta temática não foram particularmente animadoras. O facto de a protecção civil (e, inerentemente, os sistemas de alerta) constituir uma competência exclusivamente nacional conduziu a que alguns países não vislumbrassem, de imediato, a maisvalia de uma abordagem integrada a nível europeu. Adicionalmente, a existência demetooblogias de aviso à população fortemente enraizadas em países do Norte e Leste Europeu (emmuitos casos decorrentes de procedimentos e metodologias adoptados desde o tempo da guerra fria) levou a que se tivesse verificadb alguma resistência, nomeadamente quando se abordava o estabelecimento de sinais comuns europeus de aviso à população.

Estas circunstâncias suscitaram um elevado esforço negocial por parte da Presidência Portuguesa que trabalhou individualmente com os Estados-Membros mais relutantes, no sentido de melhor percepcionar as suas preocupações e de estabelecer as bases necessárias à obtenção de compromissos. O fruto desse trabalho surgiu em Dezembro de 2007, quando os Ministros da Administração Intema dos 27 Estados-Membros adoptaram por unanimidade Conclusões do Conselho sobre esta matéria, as quais traduzem compromissos políticos e linhas de orientação a seguir para o estabelecimento e desenvolvimento de sistemas de alerta precoce na União Erropeia. Tais Conclusões encontram-se agora em fase inicial de implementação, cabendo aos Estados-Membros e à Comissão Europeia, sob vigilância das próximas Presidências do Conselho, desencadearem os processos de concretização dos procedimentos e acções preconizados.
Ao atingir o objectivo a que se propôs, Portugal contribuiu para criar as bases para uma União Europeia cada vez mais assente numa cultura de segurança, prevenção e protecção. Fmbora se tenha a consciência de que apenas foi dado um pequeno passo, julga-se que se conseguiu imprimir a energia de activação necessária para quebrar a inércia e iniciar um processo de mudança, tomando viável o que até há pouco não o era.

De um estado inicial em que Estados-Membros e Comissão Europeia andavam como que em círculos, sem rumo traçado, passou-se para um quadro estratégico que defineprincípios, linhas de orientação e objectivos concretos. É certo que julgar que os sistemas de alerta precoce vão contribuir para uma meta de "zero consequências" após cada catástrofe será tão utópico como descabrir o pote cheio de auro no final do arco-íris, tão ilusoriamente retratado nos contos de fadas. Na realidade, o homem não controla a Natureza e, muitas vezes, não exerce também o autocontrolo sobre as suas próprias actividades. Por isso, as emergências continuarão a existir. Todavia, sistemas de alerta precoce mais robustos e adequados poderão contribuir significativamente para a redução progressiva da vulnerabilidade dos Estados-Membros da União Europeia.

Não será, necessariamente, umprocesso célere. Mas será um processo sustentado, assente num trabalho conjunto diário e no permanente estabelecimento de "pontes" entre os Estadbs-Menbros, que contribuam quer para o fortalecimento de relações bil laterais, quer para a instalação de uma verdadeira cul tura comnitária. Poderá demorar um, cinco ou dez anos a concretizar alguma alteração de mentalidades. Mas quando finalmente toca a estratégia estiver implenentada ter-seão obtido mais-valias para uma população cada vez mais exigente de segurança e carente de estabilididade. Assim saiba a União frrropeia ter a coragende continuar a estimular este processo tão recentemente iniciadb. 